\title{
A score that predicts 1-year functional status in patients with anti-NMDA receptor encephalitis
} Ramani Balu, MD, PhD, Lindsey McCracken, MS, Eric Lancaster, MD, PhD, Francesc Graus, MD, PhD,
Josep Dalmau, MD, PhD, ${ }^{\star}$ and Maarten J. Titulaer, MD, PhD*

Neurology ${ }^{\circledR}$ 2019;92:e244-e252. doi:10.1212/WNL.0000000000006783

\section{Abstract}

\section{Objective}

To construct a grading score that predicts neurologic function 1 year after diagnosis of antiNMDA receptor (NMDAR) encephalitis.

\section{Methods}

Three hundred eighty-two patients with detailed information and functional status at 1 year were studied. Factors associated with poor status (defined as modified Rankin Scale score $\geq 3$ ) were identified and incorporated into a multivariate logistic regression model. This model was used to develop a 5-point prediction score, termed the anti-NMDAR Encephalitis One-Year Functional Status (NEOS) score.

\section{Results}

Intensive care unit admission $(p<0.001)$, treatment delay $>4$ weeks $(p=0.012)$, lack of clinical improvement within 4 weeks $(p<0.001)$, movement disorder $(p=0.001)$, central hypoventilation $(p<0.001)$, elevated CSF white blood cell count $(p<0.001)$, elevated CSF protein level $(p=0.027)$, and abnormal MRI $(p=0.002)$ were associated with 1 -year functional status in univariate analysis. Intensive care unit admission, treatment delay $>4$ weeks, lack of clinical improvement within 4 weeks, abnormal MRI, and CSF white blood cell count $>20$ cells $/ \mu \mathrm{L}$ were independent predictors for outcome in multivariate regression modeling. These 5 variables were assigned 1 point each to create the NEOS score. NEOS score strongly associated with the probability of poor functional status at 1 year ( $3 \%$ for 0 or 1 point to $69 \%$ for 4 or 5 points, $p<0.001)$.

\section{Conclusions}

The NEOS score accurately predicts 1-year functional status in patients with anti-NMDAR encephalitis. This score could help estimate the clinical course following diagnosis and may aid in identifying patients who could benefit from novel therapies.

\author{
Correspondence \\ Prof. Dalmau \\ josep.dalmau@ \\ uphs.upenn.edu
}

\section{RELATED ARTICLE}

Editorial

Forecasting outcomes in anti-NMDAR encephalitis: Clearer prognostic markers needed

Page 119

\section{MORE ONLINE}

\section{ค Podcast}

Dr. David Lapides interviews Dr. Ramani Balu on a score that predicts 1-year functional status in patients with anti-NMDA receptor encephalitis. NPub.org/alhpx4

\footnotetext{
*These authors share seniority.
}

From the Department of Neurology (R.B., L.M., E.L., J.D.) and Division of Neurocritical Care (R.B.), Perelman School of Medicine, University of Pennsylvania, Philadelphia; Department of Neurology (F.G., J.D.), Hospital Clinic, University of Barcelona/Institut d'Investigacions Biomediques August Pi i Sunyer; Institució Catalana de Recerca i Estudis Avançats (ICREA) (J.D.), Barcelona, Spain; and Department of Neurology (M.J.T.), Erasmus University Medical Center, Rotterdam, the Netherlands.

Go to Neurology.org/N for full disclosures. Funding information and disclosures deemed relevant by the authors, if any, are provided at the end of the article. The Article Processing Charge was funded by Erasmus University.

This is an open access article distributed under the terms of the Creative Commons Attribution-NonCommercial-NoDerivatives License 4.0 (CC BY-NC-ND), which permits downloading and sharing the work provided it is properly cited. The work cannot be changed in any way or used commercially without permission from the journal. 


\section{Glossary}

ICU = intensive care unit; $\mathrm{mRS}=$ modified Rankin Scale; NEOS = anti-NMDAR Encephalitis One-Year Functional Status; NMDAR = NMDA receptor; $\mathbf{W B C}=$ white blood cell.

Anti-NMDA receptor (NMDAR) encephalitis is an autoimmune neurologic disorder that occurs in association with antibodies against the GluN1 subunit of the NMDAR. ${ }^{1}$ Patients usually develop behavioral changes, psychosis, unresponsiveness, seizures, dyskinesias, autonomic dysfunction, or disordered breathing. ${ }^{1-4}$ The disease can occur in association with tumors (mostly ovarian teratoma) although in a substantial number of patients no tumor is identified. ${ }^{1,3-6}$ Despite the severity of the symptoms, which frequently lead to patients' admission to intensive care units (ICUs), ${ }^{2,4}$ aggressive immunotherapy and tumor removal (when it applies) usually result in favorable long-term outcomes. ${ }^{4,6}$ Steroids, IV immunoglobulin, or plasma exchange are commonly used as first-line immunotherapies, and rituximab and cyclophosphamide are considered when the first-line treatments fail. Using this approach, recovery to functional independence has been documented even in patients who have been unresponsive for months. ${ }^{4}$ In most patients, the process of recovery is protracted, and although ICU admission ${ }^{4}$ and delay in initiating first-line therapy ${ }^{4-6}$ are associated with outcome, there is no standardized tool that predicts long-term functional status. Such a tool could help in counseling families on expected disease severity and recovery trajectory, and in identifying subgroups of patients who may benefit from novel salvage therapies in future trials. Here, we used multivariate logistic regression modeling to develop a simple scoretermed the anti-NMDAR Encephalitis One-Year Functional Status (NEOS) score-that can predict disease severity and neurologic function at 1 year of symptom onset.

\section{Methods}

\section{Standard protocol approvals, registrations, and patient consents}

Informed consent was obtained from patients or their legal health care proxy for inclusion in an ongoing observational cohort study of autoimmune encephalitis. The institutional review boards of the University of Pennsylvania and Hospital Clinic, University of Barcelona approved all aspects of this retrospective observational study.

\section{Identification of patients with anti- NMDAR encephalitis}

We identified individuals with confirmed anti-NMDAR encephalitis from a cohort of patients who had serum and/or CSF samples sent to either the University of Pennsylvania (Philadelphia) or the Hospital Clinic, University of Barcelona (Spain) for testing of autoimmune neurologic disease markers between 2002 and 2011. Patients were diagnosed with antiNMDAR encephalitis if they had a clinical picture suggestive of this disorder, along with CSF or serum showing a characteristic pattern of reactivity with rat brain tissue and specific immunolabeling of HEK293 cells expressing GluN1 subunits of the NMDAR. ${ }^{7}$ Detailed information-including demographics, symptom onset date, clinical features, laboratory and radiographic findings, time from symptom onset to treatment initiation, time from treatment initiation to initial clinical improvement, and functional status (quantified using the modified Rankin Scale [mRS]) at 4, 8, 12, 18, and 24 months after treatment initiation-had been previously obtained for this cohort from referring physicians as part of a prior observational study. ${ }^{4}$

\section{Analysis of clinical variables}

Dichotomized functional status at 12 months was used as the dependent variable for all analyses. Good functional status was defined as $\mathrm{mRS}$ score $\leq 2$, which spans a range from no disability $(\mathrm{mRS}=0)$ to having slight disability but able to look after one's own affairs without assistance $(m R S=2)$. In contrast, poor functional status (defined as $\mathrm{mRS} \geq 3$ ) represents a continuum of function from moderate disability requiring help for activities of daily living (mRS 3) to severe disability requiring constant nursing care (mRS 5) and death (mRS 6).

We analyzed the association between the following factors and functional status: (1) demographics including age and sex; (2) presenting clinical signs including behavioral changes, memory dysfunction, speech disorders, sleep dysfunction, seizures, autonomic dysfunction, movement disorders, and central hypoventilation; (3) laboratory and radiographic findings including CSF protein and white blood cell (WBC) count, abnormal EEG, and abnormal MRI; and (4) other clinical features including presence of a tumor, need for ICU admission, time to initiation of treatment (tumor removal and/or immunotherapy) from symptom onset in weeks, and time to first documented improvement after treatment initiation in weeks. Because of the 1-year follow-up period, the maximum value for both time to treatment initiation and time to clinical improvement was 52 weeks. Four patients developed spontaneous clinical improvement before immunotherapy initiation; in these patients, the time to first documented improvement after treatment was negative. Criteria for abnormal EEG included the presence of any of the following: abnormal state changes, focal or diffuse slowing, epileptiform discharges, rhythmic slowing, extreme delta brush, ${ }^{8}$ or electrographic seizures. MRI scans were classified as abnormal based on the opinion of the referring physician; i.e., with imaging findings consistent with or suggestive of encephalitis. 9 


\section{Statistical analysis}

Dichotomous variables were analyzed using the Fisher exact test or Fisher-Freeman-Halton test (an extension of the Fisher exact test for contingency tables larger than $2 \times 2$ ), as appropriate. Distributions of continuous variables were highly skewed, precluding the use of parametric statistical testing. Therefore, continuous variables were analyzed using the Wilcoxon rank sum test. Continuous variables were dichotomized based on the median value in patients with good 1-year functional status to allow incorporation into the multivariate logistic regression model, and then iteratively adjusted to produce the best fit. We identified 32 patients in whom CSF WBC count was categorized as normal $(<5$ cells $/ \mu \mathrm{L})$, even though absolute WBC count was not recorded. In addition, 60 patients whose first-line treatment was classified as failure (defined as no clinical improvement within 4 weeks of treatment initiation) did not have a time to clinical improvement in weeks recorded. In both instances, these cases were added to the final dichotomized dataset to increase sample size and reduce selection bias.

Missing values (2.1\% of the total number of values) were imputed to increase power and reduce the risk of bias before multivariate logistic regression model construction. We used multiple imputation to create 5 sample sets with 1-year functional status included as covariate. We then constructed a multivariate logistic regression model using the final sample set containing imputed values to identify independent predictors of functional status at 1 year. We initially included all variables that were associated with functional status in univariate analysis (after imputation) with cutoff $p<0.05$, and then eliminated variables in a stepwise fashion that did not contribute to the final model (cutoff $p<0.05$ ).

A 1-year prediction score was constructed using variables in the final logistic regression model that were significantly associated with functional status. Both an unweighted score (in which each predictor of functional status was assigned 1 point) and a weighted score (in which points were assigned for each predictor proportional to its strength of association with functional status) were constructed and tested. If both scores showed significant association with functional status, preference was given to the unweighted score because of its simplicity. To avoid small groups, patients with scores of either 0 and 1 or 4 and 5 were pooled. The overall strength of association between each prediction score and functional status was assessed using the Cuzick Wilcoxon nonparametric test for trend. ${ }^{10}$ The Cuzick test for trend was also used to evaluate for changes in the distribution of NEOS scores over time. Statistical analyses were performed using Stata (version 15; StataCorp LLC, College Station, TX), SPSS (version 25; IBM Corp., Armonk, NY), and Prism (version 7; GraphPad Software, La Jolla, CA).

\section{Data availability}

Any data not published within the article are available and will be shared anonymously by request from any qualified investigator.

\section{Results}

\section{Univariate analysis of factors that predict functional status at $\mathbf{1}$ year}

Of 577 patients, 382 had data on clinical factors and 1-year functional status and were included for analysis. ${ }^{4}$ Of these 382 patients, 281 (74\%) had good functional status at 1 year, while 101 (26\%) had poor functional status. Of the 101 patients with poor functional status at 1 year, 70 were followed up to 2 years after initial presentation. In this subset with 2-year followup, $25(35 \%)$ recovered to good functional status. Tables 1 and 2 show the association between individual clinical, laboratory, and imaging factors and neurologic function at 1 year.

Among the recorded clinical factors, reduced level of consciousness $(p=0.005)$, presence of an acute movement disorder $(p=0.001)$, central hypoventilation $(p<0.001)$, need for ICU admission $(p<0.001)$, and time to first recorded clinical improvement after treatment initiation $(p<0.001)$ were all associated with poor functional status at 1 year. Delay until treatment initiation (tumor removal and/or immunotherapy) more than 4 weeks after symptom onset was also associated with poor 1-year functional status $(p=0.012)$. Of interest, although a clear majority of patients with both poor and good functional status presented with abnormal behaviors such as mania and psychosis (275 of 281 patients with good status vs 93 of 101 patients with poor status), these behaviors were more frequently observed in patients with good status at 12 months $(p=0.013)$. Sex $(p=0.45)$, tumor status $(p=$ $0.64)$, and age $(p=0.13)$ were not significantly associated with functional status at 1 year.

Of the recorded laboratory and imaging factors, abnormal MRI findings $(p=0.002)$, CSF WBC count $(p<0.001)$, and CSF protein level $(p=0.027)$ were associated with poor functional status at 1 year. EEG abnormalities did not associate with neurologic function $(p=0.31)$.

\section{Construction of the NEOS score}

We next developed a multivariate regression model to identify independent predictors of functional status at 1 year. To facilitate translation into a clinical rating scale, continuous variables were dichotomized before incorporation into the multivariate regression model. We used time from symptom onset to treatment initiation $>4$ weeks, time to initial clinical improvement from treatment initiation $>4$ weeks, CSF WBC count $>20$ cells $/ \mu \mathrm{L}$, and CSF protein $>30 \mathrm{mg} / \mathrm{dL}$ as cutoff points to create these dichotomous independent variables. Cutoff values were initially chosen as the median value observed for each variable in patients with good 1-year functional status, and then iteratively adjusted to produce the best fit.

Multivariate logistic regression after multiple imputation ( $2.1 \%$ of variables imputed) revealed 5 independent variables. These included (1) need for ICU admission, (2) no treatment initiated within 4 weeks of symptom onset, (3) lack of clinical 
Table 1 Association of binary variables with functional status

\begin{tabular}{llll}
\hline & No. (\%) & $\begin{array}{l}\text { Poor } \\
\text { functional } \\
\text { status, } \mathbf{n}(\%)\end{array}$ & $\boldsymbol{p}$ \\
\hline Sex & $315(82)$ & $86(27)$ & 0.45 \\
\hline Female & $67(18)$ & $15(22)$ & \\
\hline Male & & & 0.64 \\
\hline Tumor & $159(42)$ & $40(25)$ & \\
\hline Present & $223(58)$ & $61(27)$ & \\
\hline Absent & & &
\end{tabular}

\section{Altered behavior}

\begin{tabular}{llll}
\hline Yes & $368(96)$ & $93(25)$ & 0.013 \\
\hline No & $14(4)$ & $8(57)$ & \\
\hline Memory impairment & & & 0.17 \\
\hline Yes & $284(76)$ & $78(27)$ & \\
\hline No & $90(24)$ & $18(20)$ & 0.27 \\
\hline Speech disorder & & & \\
\hline Yes & $283(76)$ & $70(25)$ & \\
\hline No & $88(24)$ & $27(31)$ & 0.12 \\
\hline Seizure & & & \\
\hline Yes & $273(72)$ & $78(29)$ & 0.005 \\
\hline No & $104(28)$ & $21(20)$ & \\
\hline Reduced consciousness & & & \\
\hline Yes & $239(63)$ & $75(31)$ & \\
\hline No & $138(37)$ & $25(18)$ & \\
\hline
\end{tabular}

Movement disorder

\begin{tabular}{llll}
\hline Yes & $297(78)$ & $90(30)$ & 0.001 \\
\hline No & $85(22)$ & $11(13)$ & \\
\hline Sleep disturbance & & & 0.56 \\
\hline Yes & $136(52)$ & $29(21)$ & \\
\hline No & $127(48)$ & $31(24)$ & 0.063 \\
\hline Autonomic dysfunction & & & \\
\hline Yes & $177(46)$ & $55(31)$ & \\
\hline No & $205(54)$ & $47(23)$ & \\
\hline Central hypoventilation & & & \\
\hline Yes & $136(36)$ & $54(39)$ & \\
\hline No & $246(64)$ & $44(18)$ & \\
\hline Requires ICU admission & & 60.001 & \\
\hline Yes & $291(77)$ & $95(33)$ & \\
\hline No & $87(23)$ & $6(7)$ & \\
\hline
\end{tabular}

Table 1 Association of binary variables with functional status (continued)

\begin{tabular}{|c|c|c|c|}
\hline & No. (\%) & $\begin{array}{l}\text { Poor } \\
\text { functional } \\
\text { status, } \mathrm{n}(\%)\end{array}$ & $p$ \\
\hline \multicolumn{4}{|l|}{ EEG } \\
\hline Normal & $34(11)$ & $6(18)$ & 0.31 \\
\hline Abnormal & $289(89)$ & $77(27)$ & \\
\hline \multicolumn{4}{|l|}{ MRI } \\
\hline Normal & 244 (69) & $52(21)$ & 0.002 \\
\hline Abnormal & $112(31)$ & $42(38)$ & \\
\hline \multicolumn{4}{|l|}{ CSF WBC count } \\
\hline$\leq 20$ cells $/ \mu \mathrm{L}$ & $158(49)$ & $27(17)$ & $<0.001$ \\
\hline$>20$ cells $/ \mu \mathrm{L}$ & $166(51)$ & $58(35)$ & \\
\hline \multicolumn{4}{|c|}{$\begin{array}{l}\text { Time to start of } \\
\text { treatment after } \\
\text { symptom onset }\end{array}$} \\
\hline$\leq 4 \mathrm{wk}$ & $237(62)$ & $52(22)$ & 0.012 \\
\hline$>4$ wk & $145(38)$ & $49(34)$ & \\
\hline \multicolumn{4}{|l|}{$\begin{array}{l}\text { Time to initial } \\
\text { improvement }\end{array}$} \\
\hline$\leq 4 \mathrm{wk}$ & $210(56)$ & $14(7)$ & $<0.001$ \\
\hline$>4$ wk & $163(44)$ & $82(50)$ & \\
\hline
\end{tabular}

Abbreviations: ICU = intensive care unit; $\mathrm{WBC}=$ white blood cell.

improvement 4 weeks after starting treatment (tumor removal or immunotherapy), (4) presence of an abnormal MRI scan, and (5) CSF WBC count $>20$ cells $/ \mu \mathrm{L}$ (table 3 ). We used these 5 variables to construct a simple score for 1-year functional status prediction: the NEOS score. Points were assigned to each variable as follows: 1 point for requiring ICU admission, 1 point for not initiating treatment within 4 weeks of symptom onset, 1 point for lack of clinical improvement within 4 weeks of starting treatment, 1 point for an abnormal MRI scan, and 1 point for elevated WBC count. Based on these point designations, the NEOS score can range from 0 to 5. Weighting different score components based on the strength of association with outcome did not alter score sensitivity. Therefore, the unweighted score was utilized because of its simplicity. To avoid small groups with wide confidence intervals, scores with $\leq 20$ patients were combined with adjacent scores.

Of the 382 patients included, the distribution of NEOS scores was as follows: 20 patients with score $=0$; 65 patients with score $=1 ; 120$ patients with score $=2 ; 98$ patients with score $=$ $3 ; 67$ patients with score $=4$; and 12 patients with score $=5$. The NEOS score strongly predicted the probability of a good neurologic function at 1 year (figure $1 ; p<0.001$, Cuzick nonparametric test for trend). Low NEOS score (0-1) almost 
Table 2 Association of continuous variables with functional status

\begin{tabular}{|c|c|c|c|c|}
\hline & \multicolumn{2}{|l|}{ Functional status } & \multirow[b]{2}{*}{ No. } & \multirow[b]{2}{*}{$p$} \\
\hline & Poor, median (range) & Good, median (range) & & \\
\hline Age, y & $23(1$ to 85$)$ & 20 (1 to 71$)$ & 382 & 0.13 \\
\hline CSF WBC count, cells/ $\mu \mathrm{L}$ & 46 (1 to 480$)$ & $22(0$ to 465$)$ & 292 & $<0.001$ \\
\hline CSF protein, mg/dL & 34 (10 to 377$)$ & $28(10$ to 241$)$ & 204 & 0.027 \\
\hline Time to start of treatment after symptom onset, wk & $4(0$ to 52$)$ & $3(0$ to 52$)$ & 382 & 0.056 \\
\hline Time to initial clinical improvement after treatment, wk & $8(-20$ to 52$)$ & $3(-2$ to 43$)$ & 313 & $<0.001$ \\
\hline
\end{tabular}

Abbreviation: WBC $=$ white blood cell.

perfectly associated with good functional status, while higher scores associated with progressively lower probabilities of good neurologic function.

Since different treatments used for anti-NMDAR encephalitis may differentially affect outcome, we next compared the relationship between NEOS score and 1-year functional status in patients who received only first-line therapies to those who received second-line therapies. In our analyzed cohort, 252 patients received only first-line therapies (either tumor removal only, or steroids, plasma exchange, or IV immunoglobulin plus tumor removal if applicable), 102 received second-line therapies (either rituximab or cyclophosphamide) after first-line therapy failure, and 28 received no treatment during the 1-year observation period. Patients who received second-line therapies had higher overall NEOS score values (figure $2 \mathrm{~A} ; p=0.002$, Fisher-Freeman-Halton test) and were more likely to have poor functional status at 1 year (poor status in $21.7 \%$ who received first-line treatments vs $37.3 \%$ who received second-line treatments, $p=0.002$ ). However, the relationship between NEOS score and 1-year functional status was almost identical for these 2 patient groups (figure 2B; $p<0.001$ for both groups, Cuzick test for trend).

Given that treatment practices for anti-NMDAR encephalitis may have changed over time, we also analyzed the relationship between NEOS score and functional status based on the year of symptom onset. We divided the cohort into 3 groups: (1) patients with symptom onset between 1993 and 2007 ( $\mathrm{n}=$ 102), which represent time points prior to the publication of the first large case series on treatment effects and clinical outcomes in anti-NMDAR encephalitis, ${ }^{3}$ (2) patients with symptom onset between 2008 and $2009(\mathrm{n}=165)$, and (3) patients with symptom onset between 2010 and 2011 ( $\mathrm{n}=$ 102). Ten patients did not have a symptom onset date identified. Patients from later symptom onset years had lower overall NEOS score values (figure $3 \mathrm{~A} ; p=0.002$, Cuzick test for trend). However, the overall relationship between NEOS score and 1-year functional status was similar across groups (figure 3B).

\section{Discussion}

Since its initial description, remarkable progress has been made in identifying molecular mechanisms of pathogenesis and effective treatment strategies for anti-NMDAR encephalitis. This progress has transformed the disease from one in which many patients were admitted to different clinical wards for prolonged periods of time with uncertain etiologic diagnosis and substantial morbidity and mortality, ${ }^{11,12}$ to one in which most patients survive and regain functional independence. ${ }^{2,4}$ Despite this marked shift in prognosis, the slow and variable trajectory of recovery makes it difficult to assess functional status in the distant future, well after initial presentation. This uncertainty imparts significant stress onto

Table 3 Multivariate regression model and point values used for the NEOS score

\begin{tabular}{llll}
\hline Patient characteristic & Odds ratio $(\mathbf{9 5} \% \mathrm{Cl})$ & $\boldsymbol{p}$ & NEOS score points \\
\hline ICU admission required & $5.89(2.17-15.99)$ & 0.001 & 1 \\
\hline No clinical improvement after 4 wk of treatment & $12.10(6.38-22.93)$ & $<0.001$ & 1 \\
\hline No treatment within $\mathbf{4}$ wk of symptom onset & $2.52(1.39-4.55)$ & 0.002 & 1 \\
\hline Abnormal MRI & $2.20(1.21-3.98)$ & 0.009 & 1 \\
\hline CSF WBC count $>\mathbf{2 0}$ cells/ $\boldsymbol{\mu L}$ & $2.10(1.13-3.91)$ & 0.019 & 1 \\
\hline
\end{tabular}

Abbreviations: $\mathrm{Cl}$ = confidence interval; ICU = intensive care unit; NEOS = anti-NMDAR Encephalitis One-Year Functional Status; WBC = white blood cell. 
A

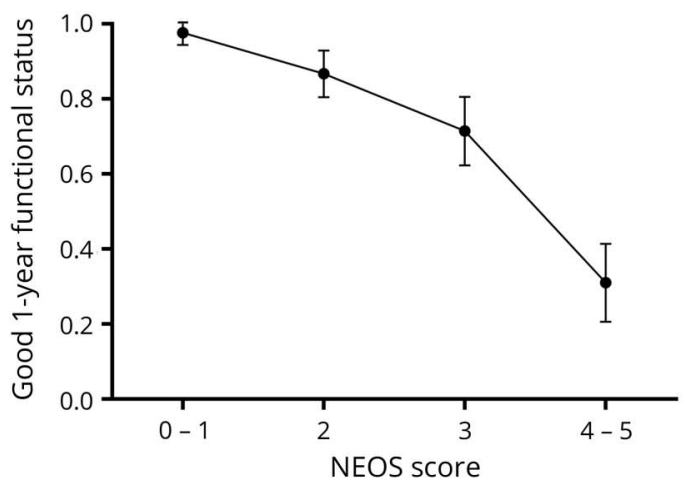

B

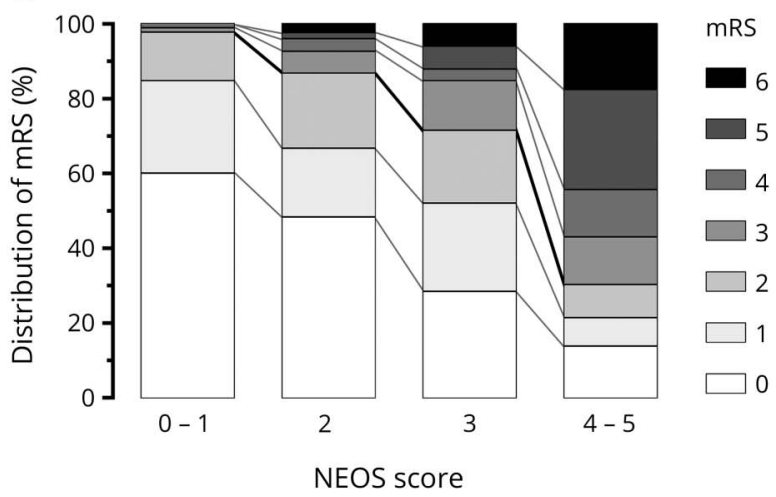

(A) Graph shows the probability of good functional status at 1 year vs NEOS score for all patients in the analyzed cohort. Increasing NEOS score is strongly associated with lower probability of good functional status at 1 year $(p<0.001$, Cuzick nonparametric test for trend). Error bars represent $95 \%$ confidence intervals for each measurement. (B) Distribution of mRS values across NEOS score values. There is a progressive shift toward higher 1 -year mRS values with increasing NEOS score. $\mathrm{mRS}$ = modified Rankin Scale; NEOS = anti-NMDAR Encephalitis One-Year Functional Status.

family members of patients. In addition, treating physicians who are unfamiliar with the natural history of the disease may be ill-equipped to counsel patients and their families on what to expect during the slow and often tortuous path to recovery.

Using data collected from a large retrospective cohort of patients with anti-NMDAR encephalitis, we identified 5 features that were independent predictors of poor functional status 1 year after symptom onset: (1) need for ICU admission, (2) lack of treatment within 4 weeks of symptom onset, (3) lack of clinical improvement within 4 weeks of starting treatment, (4) abnormal brain MRI, and (5) elevated CSF WBC count $>20$ cells $/ \mu \mathrm{L}$. We used these 5 features to develop a simple score that accurately predicts the probability of good functional status at 1 year after initial symptom presentation. The NEOS score can be calculated early in the clinical course (within 4 weeks of initiating treatment) and is readily determined using routine clinical assessments and imaging studies. It can be calculated easily at the bedside but retains the ability to discriminate differences in the probability of good functional status at 1 year over a wide range of score values.

The relationship between NEOS score and outcome did not differ between patients who received first-line and second-line therapies. We suspect that this similarity in NEOS scorebased functional status prediction across therapies reflects the fact that second-line therapies are preferentially utilized in "sicker" patients with higher disease severity, and that secondline therapies tend to be used later in patients who do not respond to first-line therapies (so-called treatment paradox or confounding by indication). ${ }^{4}$ Such patients would be expected to have higher NEOS scores, and indeed we found that the distribution of NEOS score was shifted toward higher values in patients who received second-line therapies. However, despite this shift toward higher NEOS scores, the relationship between NEOS score and functional status at 1 year remains unchanged.

We also did not find any systematic differences in the relationship between NEOS score and functional status over the years. There has been a progressive shift to lower NEOS scores in patients more recently diagnosed, which we suspect is driven at least in part by improved early recognition of antiNMDAR encephalitis. In addition, because of better awareness, patients with relatively milder encephalitis are being identified as having anti-NMDAR encephalitis. However, since treatment delays are incorporated into NEOS score calculation, the overall relationship between NEOS score and outcome has not changed over time.

We previously showed that patients older than 45 years who develop anti-NMDAR encephalitis have poorer overall outcomes $^{13}$; however, we did not find that age was a significant predictor of 1-year functional status in the current study. The overall lack of association between age and functional status may be attributable to the fact that (1) outcomes are bimodally distributed across age (i.e., both younger children and older adults tend to have worse clinical outcomes ${ }^{4,13}$ ) and (2) the effect of age on functional status is at least in part due to substantial delays in diagnosis and treatment in older patients. ${ }^{13}$ Also, although our initial work suggested that patients with tumor-associated disease had better outcomes, ${ }^{3}$ we have since found no association between tumor status and overall outcome: the apparent improved outcomes initially recognized in tumor-associated cases was biased by longer and more intensive follow-up in patients in whom a tumor was identified, and no longer significant in multivariate analysis. ${ }^{4}$ Also, the increasing recognition of nontumor-associated cases, coupled with the aggressive use of second-line 
Figure 2 Impact of first- and second-line therapies on NEOS score

A

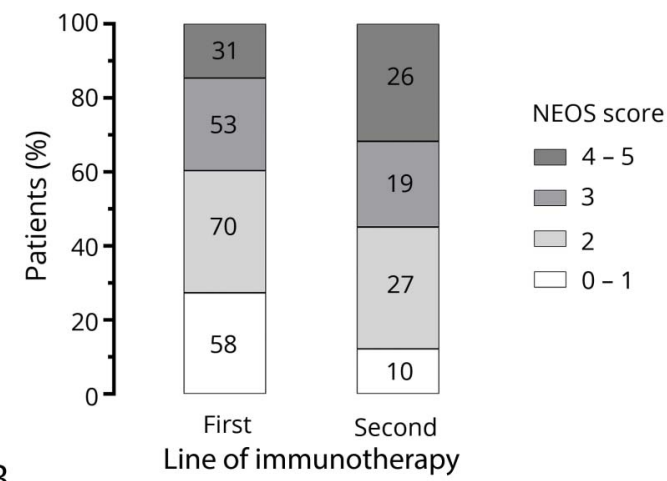

B

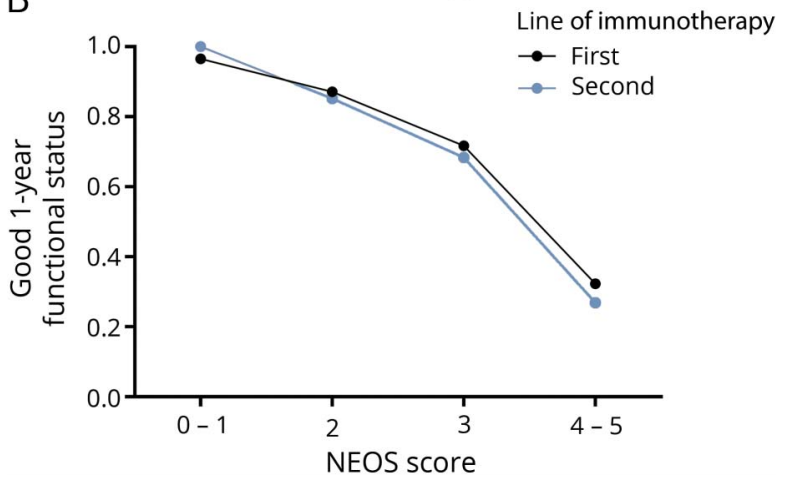

(A) Distribution of NEOS scores in patients who received only first-line therapies and in patients who received second-line therapies. There is a shift toward higher NEOS scores in patients who received second-line therapies. (B) Relationship between NEOS score and probability of good functional status at 1 year is similar in patients who received only first-line therapies compared to those who received second-line therapies. NEOS = antiNMDAR Encephalitis One-Year Functional Status.

immunotherapies, may account for a progressive improvement and equalization of overall outcomes between tumorand nontumor-associated cases. Further work is required to clarify these issues.

We and others previously found an association between increasing delay in treatment initiation and higher likelihood of poor outcome. ${ }^{4,5}$ In line with these observations, we found here that not initiating treatment within 4 weeks of symptom onset strongly predicted poor 1-year functional status. However, we caution against extrapolating this result to mean that a delay in treatment of more than 4 weeks inevitably leads to a poor outcome. There is evidence of patients whose diagnosis was missed or had prolonged diagnostic delays and eventually recovered or substantially improved. ${ }^{12}$ A reasonable treatment strategy is therefore to initiate immunotherapy and tumor removal (if applicable) as soon as an unambiguous diagnosis has been made. ${ }^{9}$

We chose to assess functional status at 1 year since it represents a time well after initial symptom presentation, and because the natural history of disease progression and clinical recovery occurs within 1 year in most patients. However, it is important to note that functional status at 1 year should not be taken to represent the ultimate clinical outcome. Patients with poor functional status at 1 year may still progress to recovery in the future, ${ }^{4}$ and we strongly caution against using the NEOS score as a tool for guiding decisions about withdrawal of care or clinical resource allocation in patients with prolonged hospitalizations. Even among the group of patients with the highest NEOS score, 32\% were functionally independent (i.e., "good" functional status with mRS score $\leq 2$ ) 1 year after symptom onset. In addition, of the patients in our cohort with poor functional status at 1 year who were followed up to 2 years, a significant proportion (35\%) recovered to good functional status at 2 years. Given this, it is reasonable to assume that some proportion of the patients with poor neurologic function at 2 years might ultimately recover with even longer follow-up. One-year functional status should therefore be viewed as a snapshot in time that allows physicians to gauge the velocity of clinical improvement, rather than the final expected outcome.

Our study has several limitations. Functional status assignment could be susceptible to recall bias since in some cases, $\mathrm{mRS}$ values were calculated retrospectively by referring

Figure 3 Distribution of NEOS score and relationship to outcome over time

A
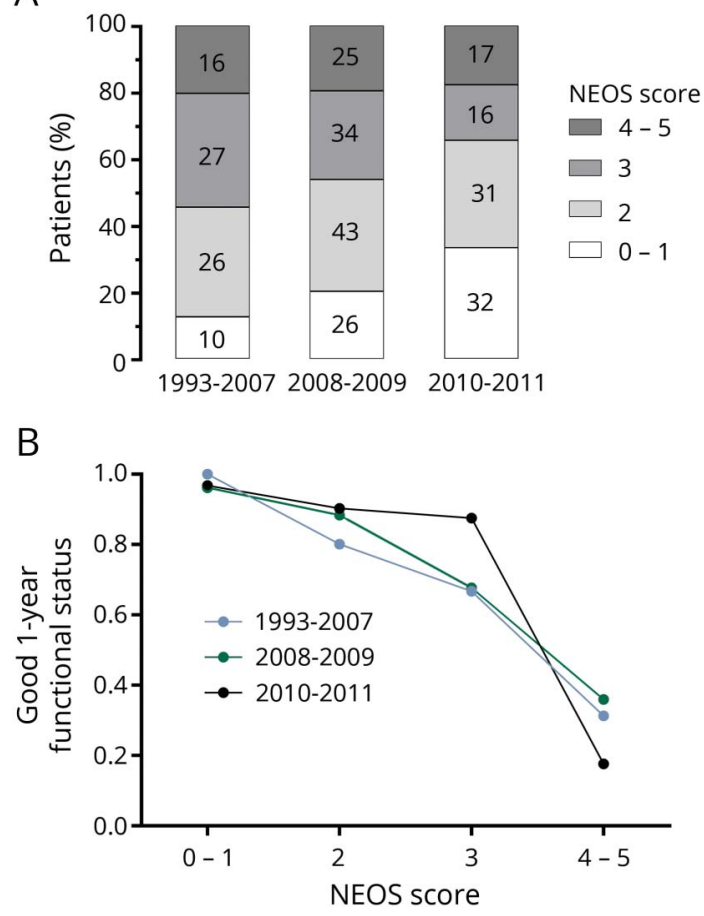

(A) Distribution of NEOS scores stratified by year of symptom onset. Over time, there is a shift toward lower NEOS score values in patients with more recent symptom onset. (B) Relationship between NEOS score and probability of good functional status at 1 year is similar across different groups. NEOS = anti-NMDAR Encephalitis One-Year Functional Status. 
Appendix 1 Author contributions

\begin{tabular}{|c|c|c|c|}
\hline Name & Location & Role & Contribution \\
\hline $\begin{array}{l}\text { Ramani Balu, } \\
\text { MD, PhD }\end{array}$ & University of Pennsylvania, Philadelphia & Author & $\begin{array}{l}\text { Design/conceptualization of the study, analyzed and interpreted } \\
\text { the data, created the figures, drafted the manuscript }\end{array}$ \\
\hline $\begin{array}{l}\text { Lindsey } \\
\text { McCracken, MS }\end{array}$ & University of Pennsylvania, Philadelphia & Author & Data collection, revised the manuscript \\
\hline $\begin{array}{l}\text { Eric Lancaster, } \\
\text { MD, PhD }\end{array}$ & University of Pennsylvania, Philadelphia & Author & Interpreted the data, revised the manuscript \\
\hline $\begin{array}{l}\text { Francesc Graus, } \\
\text { MD, PhD }\end{array}$ & University of Barcelona, Spain & Author & Interpreted the data, revised the manuscript \\
\hline $\begin{array}{l}\text { Josep Dalmau, } \\
\text { MD, PhD }\end{array}$ & $\begin{array}{l}\text { University of Pennsylvania, Philadelphia, } \\
\text { and ICREA University of Barcelona, Barcelona, } \\
\text { Spain }\end{array}$ & Author & $\begin{array}{l}\text { Design/conceptualization of the study, analyzed and interpreted } \\
\text { the data, drafted the manuscript }\end{array}$ \\
\hline $\begin{array}{l}\text { Maarten Titulaer, } \\
\text { MD, PhD }\end{array}$ & $\begin{array}{l}\text { Erasmus University Medical Center, Rotterdam, } \\
\text { the Netherlands }\end{array}$ & Author & $\begin{array}{l}\text { Design/conceptualization of the study, data collection, analyzed and } \\
\text { interpreted the data, created the figures, drafted the manuscript }\end{array}$ \\
\hline
\end{tabular}

physicians. Our cohort only includes patients referred to the University of Pennsylvania or the University of Barcelona for studies on autoimmune neurologic disease, which could introduce a selection bias. However, at the time of sample collection, our institutions provided the majority of testing of anti-NMDAR encephalitis worldwide. Samples were collected from 200 centers from 35 different countries. While this could be viewed as a particular strength of this study, a potential limitation of this wide referral base is that variations in treatment approaches across centers could affect outcome. Despite this concern, we believe that the overall approach to treatment was similar across referral centers. Patients were all treated in a stepwise fashion, with second-line therapies used only in cases in which no clinical response was seen to first-line therapies. Second, because of the limited options for antibody testing at the time of sample collection, referring physicians often received guidance on treatment approaches from our centers after specimen testing. In this way, patients from these disparate referral centers were funneled into a similar approach to treatment. Finally, future studies using other prospectively collected cohorts are needed to establish external validity of the NEOS score. In addition, incorporating biomarkers that associate with the response to treatment ${ }^{14}$ could further improve the score's ability to predict ultimate clinical outcome.

In addition to aiding families and treating physicians, the NEOS score could also be used to identify subsets of patients who may benefit from novel therapies in future clinical trials. Indeed, the standardization of treatment protocols for antiNMDAR encephalitis, and other autoimmune encephalitis syndromes, brings the opportunity to test novel immunomodulatory agents that may modify disease course. Unbiased identification of appropriate patients using standardized metrics will be essential for proper trial design, and will ultimately aid in the development of novel treatment strategies that may allow for faster trajectories of recovery.

\section{Acknowledgment}

The authors thank Dr. Bob Roozenbeek for his statistical advice.

\section{Study funding}

This study was supported in part by Instituto Carlos III/ FEDER (FIS PI15/00377 [F.G.]; FIS PI14/00203 [J.D.]); CIBERER CB15/00010 (J.D.); NIH RO1NS077851 (J.D.); NIH K08 NS-075142-01A1 (E.L.); Fundació CELLEX (J.D.); Dutch Epilepsy Foundation (NEF, project 14-19 [M.T.]); and Netherlands Organisation for Scientific Research (NWO/ZonMW, Memorabel program and Veni incentive [M.T.]).

\section{Disclosure}

R. Balu and L. McCracken report no disclosures relevant to the manuscript. E. Lancaster has consulted for Grifols Inc., Novartis Inc., and Merck Inc., and received a research grant from Grifols Inc. F. Graus receives royalties from EUROIMMUN AG for the use of IgLON5 as an autoantibody test. J. Dalmau receives royalties from Athena Diagnostics for the use of Ma-2 as an autoantibody test and from EUROIMMUN AG for the use of NMDA, $G A B A_{B}$ receptor, $G_{A B A}$ receptor, DPPX, and IgLON5 as autoantibody tests; he received an unrestricted research grant from EUROIMMUN AG. M. Titulaer has a patent for testing of anti-GABA $A_{B} R$ and antiKCTD antibodies, and has received research funds for serving on a scientific advisory board of MedImmune LLC, for consultation at Guidepoint Global LLC, and an unrestricted research grant from EUROIMMUN AG. Go to Neurology.org/ $\mathrm{N}$ for full disclosures.

\section{Publication history}

Received by Neurology May 22, 2018. Accepted in final form September 5, 2018.

\section{References}

1. Dalmau J, Graus F. Antibody-mediated encephalitis. N Engl J Med 2018;378: 840-851.

2. Dalmau J. NMDA receptor encephalitis and other antibody-mediated disorders of the synapse: the 2016 Cotzias Lecture. Neurology 2016;87:2471-2482. 
3. Dalmau J, Gleichman AJ, Hughes EG, et al. Anti-NMDA-receptor encephalitis: case series and analysis of the effects of antibodies. Lancet Neurol 2008;7: 1091-1098.

4. Titulaer MJ, McCracken L, Gabilondo I, et al. Treatment and prognostic factors for long-term outcome in patients with anti-NMDA receptor encephalitis: an observational cohort study. Lancet Neurol 2013;12:157-165.

5. Irani SR, Bera K, Waters P, et al. N-methyl-D-aspartate antibody encephalitis: temporal progression of clinical and paraclinical observations in a predominantly nonparaneoplastic disorder of both sexes. Brain 2010;133:1655-1667.

6. Viaccoz A, Desestret V, Ducray F, et al. Clinical specificities of adult male patients with NMDA receptor antibodies encephalitis. Neurology 2014;82: $556-563$.

7. Dalmau J, Lancaster E, Martinez-Hernandez E, Rosenfeld MR, Balice-Gordon R. Clinical experience and laboratory investigations in patients with anti-NMDAR encephalitis. Lancet Neurol 2011;10:63-74.
8. Schmitt SE, Pargeon K, Frechette ES, Hirsch LJ, Dalmau J, Friedman D. Extreme delta brush: a unique EEG pattern in adults with anti-NMDA receptor encephalitis. Neurology 2012;79:1094-1100.

9. Graus F, Titulaer MJ, Balu R, et al. A clinical approach to diagnosis of autoimmune encephalitis. Lancet Neurol 2016;15:391-404.

10. Cuzick J. A Wilcoxon-type test for trend. Stat Med 1985;4:87-90.

11. Dalmau J, Tuzun E, Wu HY, et al. Paraneoplastic anti-N-methyl-D-aspartate receptor encephalitis associated with ovarian teratoma. Ann Neurol 2007;61:25-36.

12. Iizuka T, Sakai F, Ide T, et al. Anti-NMDA receptor encephalitis in Japan: long-term outcome without tumor removal. Neurology 2008;70:504-511.

13. Titulaer MJ, McCracken L, Gabilondo I, et al. Late-onset anti-NMDA receptor encephalitis. Neurology 2013;81:1058-1063.

14. Leypoldt F, Hoftberger R, Titulaer MJ, et al. Investigations on CXCL13 in anti-Nmethyl-D-aspartate receptor encephalitis: a potential biomarker of treatment response. JAMA Neurol 2015;72:180-186. 


\section{Neurology}

\section{A score that predicts 1-year functional status in patients with anti-NMDA receptor encephalitis \\ Ramani Balu, Lindsey McCracken, Eric Lancaster, et al.}

Neurology 2019;92;e244-e252 Published Online before print December 21, 2018

DOI 10.1212/WNL.0000000000006783

\section{This information is current as of December 21, 2018}

\section{Updated Information \&} Services

References

Citations

Subspecialty Collections

Permissions \& Licensing

Reprints including high resolution figures, can be found at: http://n.neurology.org/content/92/3/e244.full

This article cites 14 articles, 5 of which you can access for free at: http://n.neurology.org/content/92/3/e244.full\#ref-list-1

This article has been cited by 4 HighWire-hosted articles: http://n.neurology.org/content/92/3/e244.full\#\#otherarticles

This article, along with others on similar topics, appears in the following collection(s):

Autoimmune diseases

http://n.neurology.org/cgi/collection/autoimmune_diseases

Critical care

http://n.neurology.org/cgi/collection/critical_care

Encephalitis

http://n.neurology.org/cgi/collection/encephalitis

Paraneoplastic syndrome

http://n.neurology.org/cgi/collection/paraneoplastic_syndrome

Prognosis

http://n.neurology.org/cgi/collection/prognosis

Information about reproducing this article in parts (figures,tables) or in its entirety can be found online at:

http://www.neurology.org/about/about_the_journal\#permissions

Information about ordering reprints can be found online:

http://n.neurology.org/subscribers/advertise

Neurology ${ }^{\circledR}$ is the official journal of the American Academy of Neurology. Published continuously since 1951 , it is now a weekly with 48 issues per year. Copyright Copyright (C) 2018 The Author(s). Published by Wolters Kluwer Health, Inc. on behalf of the American Academy of Neurology.. All rights reserved. Print ISSN: 0028-3878. Online ISSN: 1526-632X.

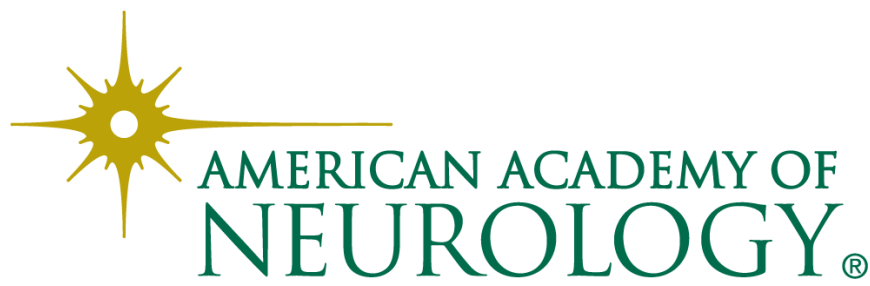

